\title{
Oxidative Layer-By-Layer Multilayers Based on Metal Coordination: Influence of Intervening Graphene Oxide Layers
}

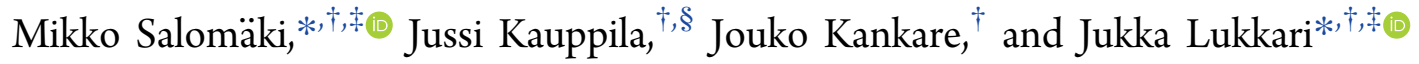 \\ ${ }^{\dagger}$ Laboratory of Materials Chemistry and Chemical Analysis, Department of Chemistry, University of Turku, Vatselankatu 2, \\ FI-20014 Turku, Finland \\ ${ }^{\ddagger}$ Turku University Centre for Materials and Surfaces (MATSURF), University of Turku, FI-20014 Turku, Finland
}

Supporting Information

ABSTRACT: Layer-by-layer (LbL) fabricated oxidative multilayers consisting of successive layers of inorganic polyphosphate (PP) and Ce(IV) can electrolessly form thin conducting polymer films on their surface. We describe the effect of substituting every second $\mathrm{PP}$ layer in the $(\mathrm{PP} / \mathrm{Ce})$ multilayers for graphene oxide (GO) as a means of modifying the structure and mechanical properties of these $(\mathrm{GO} / \mathrm{Ce} / \mathrm{PP} / \mathrm{Ce})$ films and enhancing their growth. Both types of $\mathrm{LbL}$ films are based on reversible coordinative bonding between the metal ions and the oxygenbearing groups in $\mathrm{PP}$ and $\mathrm{GO}$, instead of purely electrostatic interactions. The GO incorporation leads to the doubling of the areal mass density and to a dry film thickness close to $300 \mathrm{~nm}$ after $4(\mathrm{GO} / \mathrm{Ce} / \mathrm{PP} / \mathrm{Ce})$ tetralayers. The film roughness increases

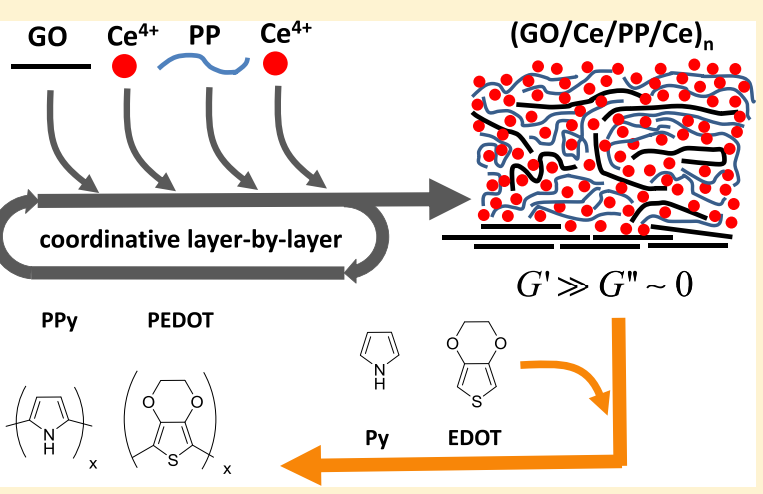
significantly with thickness. The (PP/Ce) films are soft materials with approximately equal shear storage and loss moduli, but the incorporation of GO doubles the storage modulus. PP displays a marked terminating layer effect and practically eliminates mechanical losses, making the $(\mathrm{GO} / \mathrm{Ce} / \mathrm{PP} / \mathrm{Ce})$ films almost pure soft elastomers. The smoothness of the (PP/Ce) films and the PP-termination effects are attributed to the reversible coordinative bonding. The $(\mathrm{GO} / \mathrm{Ce} / \mathrm{PP} / \mathrm{Ce})$ films oxidize pyrrole and 3,4-ethylenedioxythiophene (EDOT) and form polypyrrole and PEDOT films on their surfaces. These polymer films are considerably thicker than those formed using the (PP/Ce) multilayers with the same nominal amount of cerium layers. The GO sheets interfere with the polymerization reaction and make its kinetics biphasic. The (GO/Ce) multilayers without PP are brittle and thin.

\section{INTRODUCTION}

The sequential layer-by-layer ( $\mathrm{LbL}$ ) assembly is one of the most facile and versatile techniques for thin-film fabrication. ${ }^{1-3}$ It is normally based on electrostatic interactions between the components but, for example, hydrogen bonding, coordination or covalent bonding, host-guest, charge transfer, and biological interactions have also been used. It does not require sophisticated experimental setups or strictly controlled ambient conditions and, in its simplest form called dip-LbL, it can be carried out simply by dipping the substrate successively into dilute solutions of the components. The thickness of the formed film is usually in the range of ca. $10-100 \mathrm{~nm}$. In very thin multilayers, the film properties are governed by the substrate-film (zone I) and the film-ambient (zone III) interfaces, while the bulk of the film (zone II) dominates in thick multilayers. ${ }^{4}$

Thick multilayers usually require hundreds of layers, which can be very time-consuming, and a rapid and facile fabrication of thick LbL films is one of the challenges in the field. ${ }^{5}$ There are, basically, two major approaches for the generation of thick films using the LbL technique. First, the time required for the assembly of an individual layer can be decreased. While 10-30 min per layer are required in the traditional dip-LbL, this time can be cut down even by a factor of 100 by using the spinassisted LbL, ${ }^{6}$ spray-assisted $\mathrm{LbL}^{7}{ }^{7}$ or spin- and spray-assisted $\mathrm{LbL}^{8}$ techniques. Even though the assembled individual layers are thin, the greatly increased assembly rate allows the generation of films with hundreds of layers in a few hours. Second, the thickness of individual layers may be increased. In special cases, this can be done by a careful control of the solution $\mathrm{pH}$ or a selection of the counterions. ${ }^{9-12}$ A more general approach is to use polyelectrolytes that give rise to an exponential growth of the multilayer, caused by a vertical diffusion of some component in and out of the film during the assembly process. ${ }^{13}$ For conventional polyanion-polycation pairs, the change from the linear to the exponential regime can be effected by an increase of the deposition temperature ${ }^{5,14}$ or ionic strength. ${ }^{15,16}$ In fact, LbL films formed from polyelectrolytes (polyelectrolyte multilayers, PEMs) generally exhibit exponential growth in the beginning of the build-up process,

Received: August 16, 2018

Revised: September 25, 2018

Published: October 2, 2018 
and the transition to the linear growth occurs at some thickness because of a restricted diffusion within the bulk of the film. ${ }^{14,17}$ Most polyelectrolyte pairs exhibiting enhanced exponential growth at room temperature are biological polyelectrolytes, which may not be appropriate for special applications or are susceptible to chemical or biological degradation. Another approach to thick LbL films with only a few layers utilizes preformed polyelectrolyte complexes as components. ${ }^{18}$ Charged platelike particles, for example, montmorillonite (MTM) clay sheets, may offer an alternative rapid route to thick multilayers, and a special three-component system consisting of poly(ethyleneimine) (PEI), poly(acrylic acid) (PAA), and MTM has been shown to exhibit exponential growth. ${ }^{19}$ The dip-LbL technique generally leads to a larger film thickness than the other LbL techniques, which usually follow the linear growth mode. ${ }^{20}$ However, exponential growth has also been observed during spray-assisted LbL. ${ }^{21}$

Another challenge with LbL films is the control of their mechanical properties. They play an important role in many applications and, for example, in electronics hard and maximally durable films may be required, whereas soft multilayers are preferable in biorelated applications. The mechanical properties can be modulated, for example, by the use of stiff polyelectrolytes, incorporation of nanoobjects (particles, sheets, and fibers), changing the assembly $\mathrm{pH}$ or ionic strength, and by chemical or photochemical crosslinking. ${ }^{22}$ Graphene oxide (GO) single or few-layer sheets can be easily produced in large quantities and, although weaker than graphene itself, GO is still a strong high-modulus material. ${ }^{23} \mathrm{GO}$ sheets have been used in polymer composites and LbL films, and they can significantly stiffen the matrix material already at a low weight fraction. ${ }^{24-27}$ This is a general phenomenon in all graphene-based polymer nanocomposites, and the percolation threshold for randomly oriented sheets is usually very low, of the order of $1 \mathrm{w} / \mathrm{w} \% .^{28,29}$ The mechanical properties of thin films can be conveniently studied using quartz crystal resonators (QCRs). A widely used technique is based on the measurement of the energy dissipation of a QCR microbalance covered with a film (QCM-D). ${ }^{30-32}$ On the other hand, we have shown that the measurement of the local acoustic impedance on the film/resonator interface $\left(\zeta_{0}\right)$ is an excellent model-independent method for the characterization of the viscoelastic properties of growing films. ${ }^{9,10,33-35}$ The local acoustic impedance is a complex quantity $\left(\zeta_{0}=\zeta_{0}^{\prime}+\mathrm{j} \zeta_{0}^{\prime \prime}\right)$, which is given in units of Rayls ( 1 Rayl $=1 \mathrm{~kg} \mathrm{~m}^{-2} \mathrm{~s}^{-1}$ ). A key parameter describing the mechanical properties of a soft film is the complex shear modulus $G_{f}=G_{f}^{\prime}+j G_{f}^{\prime \prime}$, where the real part $G_{\mathrm{f}}^{\prime}$ is the storage modulus and the imaginary part $G_{\mathrm{f}}^{\prime \prime}$ is the loss modulus. The shear modulus and the film mass can be obtained from the surface acoustic impedance data measured during the film formation. However, the viscoelasticity of the film (and the fluid it is immersed in) affects the frequency of the quartz resonator and causes a deviation from the classic Sauerbrey equation. ${ }^{36,37}$ In this case, the areal mass density of the film on the resonator surface $(m)$ can be calculated using the medium-corrected Sauerbrey equation, which, for an elastic film in contact with a low-viscosity Newtonian fluid, can be approximated by

$$
m=\frac{\Delta \operatorname{Im}\left(\zeta_{0}\right)}{\omega}
$$

where $\omega$ is the nominal angular frequency of the resonator and $\Delta \operatorname{Im}\left(\zeta_{0}\right)$ is the change in the imaginary part of the surface acoustic impedance. ${ }^{14}$

The third challenge is to introduce functionality into the LbL films. Redox active, ion-responsive, and enzymecontaining multilayers are well-known, ${ }^{1}$ but relatively little attention has been paid to chemically reactive films, in which the film components themselves take part in a chemical reaction. We have studied oxidative [polyphosphate(PP)/Ce] multilayers consisting of $\mathrm{Ce}(\mathrm{IV})$ and $\mathrm{PP}$, which allow an electroless polymerization of monomers, such as pyrrole (Py), aniline, 3,4-ethylenedioxythiophene (EDOT), or 5,6-dihydroxyindole, to conducting polymer or melanin-type films on their surface. ${ }^{38-40}$ Cerium acts as an oxidant in these films, but it also brings resilience to the film structure. In these oxidative multilayers, the limiting factor is the amount of oxidants in the film. Therefore, in order to obtain higher oxidizing capacity and improve the mechanical properties of the film, we have studied the effect of introducing GO sheets into the film. In this work, we show that replacing every second PP layer in a (PP/Ce) multilayer with GO sheets enhances the film growth in dip-LbL. The multilayers remain oxidatively active and generate thick electroactive conducting polymer films on their surface. The GO sheets affect the growth and reactions of oxidative multilayers, enhance the elasticity of the films, and bring about a clear terminating layer effect. In addition, both the $(\mathrm{PP} / \mathrm{Ce})$ and $(\mathrm{GO} / \mathrm{Ce} / \mathrm{PP} / \mathrm{Ce}) \mathrm{LbL}$ films represent rather little studied metal-polymer LbL multilayers based on metal coordination bonds, ${ }^{41-46}$ and this work yields more insight into the structure and properties of such films.

\section{EXPERIMENTAL SECTION}

Materials. Sodium chloride (J. T. Baker), sodium nitrate (Riedelde Haën), potassium permanganate (Merck), cerium(IV)ammonium nitrate (Alfa Aesar), natural graphite flakes (mesh 325, 99.8\%; Alfa Aesar), $N$-trimethoxysilylpropyl- $N, N, N$-trimethylammonium chloride (TMSPA, 50\% in methanol, ABCR), methanol (J. T. Baker and Sigma-Aldrich), sulfuric acid (J. T. Baker and Sigma-Aldrich), Py (Aldrich), 3,4-ethylene dioxythiophene (Bayer), 2-mercaptoethylamine (Sigma), and hydrogen peroxide (30\%, J. T. Baker) were used as received. Potassium polyphosphate $\left(99.8 \%, \mathrm{ABCR}, M_{\mathrm{w}} \approx 2 \mathrm{MDa}\right)$ was washed with water and dried in oven to remove any residual phosphoric acid. GO was prepared from graphite by using the modified Hummers method (see the Supporting Information for details). ${ }^{47}$ All aqueous solutions were prepared using water distilled twice in quartz vessels. Glass substrates were cut from microscope slides (Menzel-Gläser) and silicon substrates from phosphorus-doped $\mathrm{Si}(100)$ wafers (Okmetic, Finland).

Layer-By-Layer Film Fabrication. Thin films were formed on microscope glasses, quartz cuvette walls, and silicon wafers. Substrates were cleaned in a Piranha solution (a 3:1 volume ratio of $\mathrm{H}_{2} \mathrm{SO}_{4}$ and $30 \% \mathrm{H}_{2} \mathrm{O}_{2}$; CAUTION-Piranha is highly corrosive and generates heat; it reacts violently with organic materials and should not be stored in tightly closed vessels) and rinsed with water. After drying in oven, the substrates were immersed for a few minutes in a 5\% TMSPA methanol solution and washed with methanol and water in order to form a positively charged surface on the substrates. In the LbL selfassembly, $10 \mathrm{mM}$ cerium ammonium nitrate and $10 \mathrm{mM}$ PP (a fresh solution in order to minimize the effect of hydrolysis, containing 0.1 $\mathrm{M} \mathrm{NaCl}$, stirred overnight before use $)^{38-40}$ aqueous solutions, and a $0.15 \mathrm{mg} / \mathrm{mL} \mathrm{GO}$ aqueous suspension were used. For spectroscopic (on the walls of a quartz cuvette; all reported absorbance values refer to one wall only) and thickness measurements, the substrates (aminosilanized quartz and silicon wafer) were successively covered with the component solutions for $15 \mathrm{~min}$ and rinsed with water between the layers for $6-8 \mathrm{~min}$. The films studied using quartz crystal 
impedance were similarly deposited on 2-mercaptoethyl aminetreated gold-plated quartz crystals in a flow-through cell either manually (thin films) or using a house-made automatic LbL and QC impedance system (thick films; washing time $100 \mathrm{~s}$ ).

Polymerization of Py and EDOT. Py or EDOT were used as 10 $\mathrm{mM}$ aqueous solutions with $\mathrm{pH}$ adjusted to 1.5 with sulfuric acid. The prepared $(\mathrm{PP} / \mathrm{Ce})$ and $(\mathrm{GO} / \mathrm{Ce} / \mathrm{PP} / \mathrm{Ce})$ multilayers were immersed in the monomer solutions, and the polymerization and cerium(IV) reduction were monitored using UV-vis spectroscopy.

Film Characterization. Optical spectra were measured using a Hewlett-Packard 8453 diode array spectrophotometer. The atomic force microscopy (AFM) images were recorded using a diCaliber AFM microscope (diCaliber, Bruker) in the tapping mode. The thickness of the dry films was measured with AFM by making a narrow slit through the film and measuring the step height at several (>20) locations. The apparatus for the automatic LbL formation and surface acoustic impedance measurements with a QCR (LbL-QCR system) and the techniques used to treat the data have been previously described in a series of papers and reviews. ${ }^{33,36,48-50}$ The AT cut $10 \mathrm{MHz}$ QCRs had a $100 \mathrm{~nm}$ gold plating (Lap-Tech, Inc., South Bowmanville, Ontario). The X-ray photoelectron spectra (XPS) were recorded as described previously. ${ }^{38}$ The polarization modulation infrared reflection-absorption spectra (PM-IRRAS) were recorded on the Nexus 870 FTIR spectrometer (Nicolet) equipped with a liquid nitrogen cooled mercury-cadmium-telluride (MCT-A) detector and a PEM-90 photoelastic modulator (HINDS Instruments); see the Supporting Information for details.

\section{RESULTS AND DISCUSSIONS}

From PP/Ce to GO/Ce/PP/Ce Multilayers. We have previously reported detailed studies on the application of oxidative $\mathrm{PP}-\mathrm{Ce}(\mathrm{IV})(\mathrm{PP} / \mathrm{Ce})$ multilayers as general oxidative platforms and characterized their mechanical properties and chemical nature. ${ }^{38,39}$ On the other hand, not much is known about their structure. Figure 1 shows the changes in the

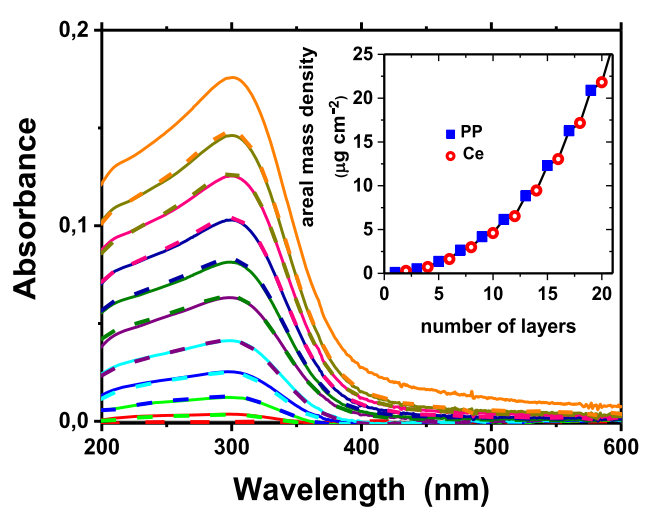

Figure 1. Growth of absorbance and areal mass density (inset) during the build-up of a (PP/Ce) multilayer. In spectra, solid and dashed lines correspond to $\mathrm{Ce}$ and $\mathrm{PP}$ as the outermost layer, respectively (same color for the ith PP and Ce layer); in mass, even and odd layers are Ce and PP, respectively. The first layer is PP in both cases.

spectrum and areal mass density (calculated using eq 1) of a (PP/Ce) film during the build-up process. Both display an exponential growth in the beginning, as reported earlier. ${ }^{38}$ The film mass increase is considerably higher upon adsorption of a PP layer than after a Ce layer, but PP addition leads only to negligible changes in the spectra, so that the multilayer spectra can be attributed to cerium species in the film. On the other hand, the aqueous solutions of $\mathrm{Ce}$ (IV) display very high molar absorptivity below $250 \mathrm{~nm}$ and a shift in the maximum around $300 \mathrm{~nm}$, which implies a different coordination environment of cerium in the films. Unfortunately, this also prevents the use of the aqueous $\mathrm{Ce}(\mathrm{IV})$ spectrum for the quantification of cerium in the film.

Introduction of 2-dimensional components in polyelectrolyte multilayers has often been shown to greatly influence their structure and properties. ${ }^{19,51-56}$ In order to increase the oxidation capacity of the (PP/Ce) films, we replaced every second PP layer with a layer of GO sheets. The schematic structures of a $(\mathrm{PP} / \mathrm{Ce})$ multilayer and that of the resulting three-component $(\mathrm{GO} / \mathrm{Ce} / \mathrm{PP} / \mathrm{Ce})$ multilayer are shown in Figure 2. It can be seen that both films contain the sequence

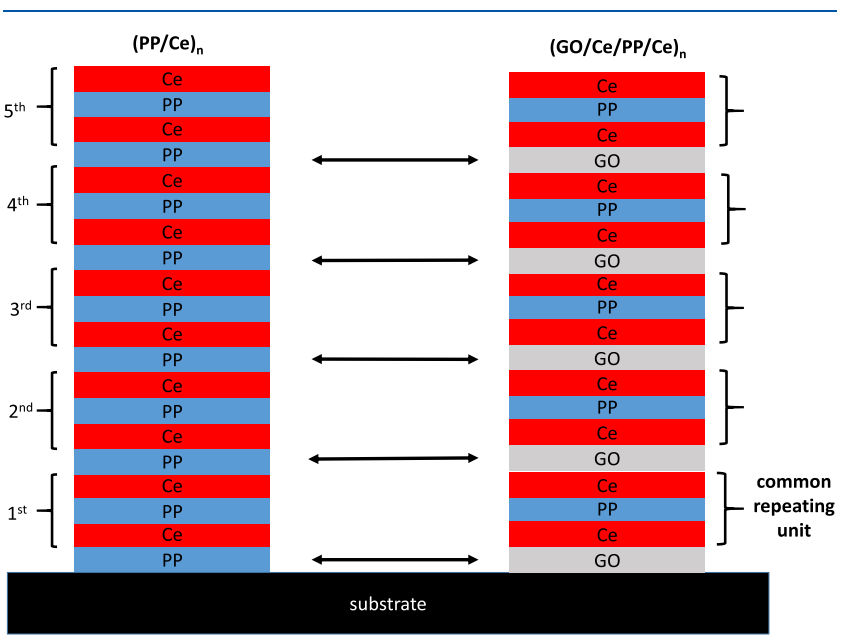

Figure 2. Schematic comparison of the (PP/Ce) and (GO/Ce/PP/ $\mathrm{Ce})$ multilayers. No effort is made to show the actual thickness or structure of the individual layers.

$\mathrm{Ce} / \mathrm{PP} / \mathrm{Ce}$ as a common repeating unit, which allows us to describe the three-component film as a two-component one consisting of alternating $\mathrm{GO}$ and $\mathrm{Ce} / \mathrm{PP} / \mathrm{Ce}$ strata.

The initial growth of the three-component multilayer on an aminosilanized wall of a quartz cuvette was followed spectrophotometrically (Figure 3a). The plot of absorbance at the spectral maximum (inset of Figure 3a) shows that the film growth is clearly exponential, and the thickness of a dry film, measured using AFM, approaches $300 \mathrm{~nm}$ already after the deposition of a few $\mathrm{GO} / \mathrm{Ce} / \mathrm{PP} / \mathrm{Ce}$ tetralayers. In its hydrated, swollen state, the film should be even thicker. At the wavelength of the absorbance maximum, $\mathrm{Ce}(\mathrm{IV})$ is the major contributor to the absorbance, especially after a PP layer. On the other hand, the addition of a GO layer has only a small effect, and PP actually decreases the absorbance. The spectra of $(\mathrm{PP} / \mathrm{Ce})$ multilayers show that $\mathrm{PP}$ is spectrally invisible and the decrease of absorbance indicates a loss of material from the film upon PP adsorption.

An independent and a more profound characterization of the growing multilayer is obtained by following the surface acoustic impedance of the film in situ (under water) with a QCR in a flow-through cell. These measurements provide data on the mechanical properties of the film and its approximate mass. The film areal mass changes, measured during the deposition of layers on a gold-plated QCR, are shown in Figure $3 \mathrm{~b}$, and confirm the exponential growth when the number of tetralayers is small. After ca. two tetralayers, the Ce layers make the major contribution to the film mass, which is in accordance with their contribution to the absorbance. However, it is contrary to the $(\mathrm{PP} / \mathrm{Ce})$ multilayers, with which the largest 

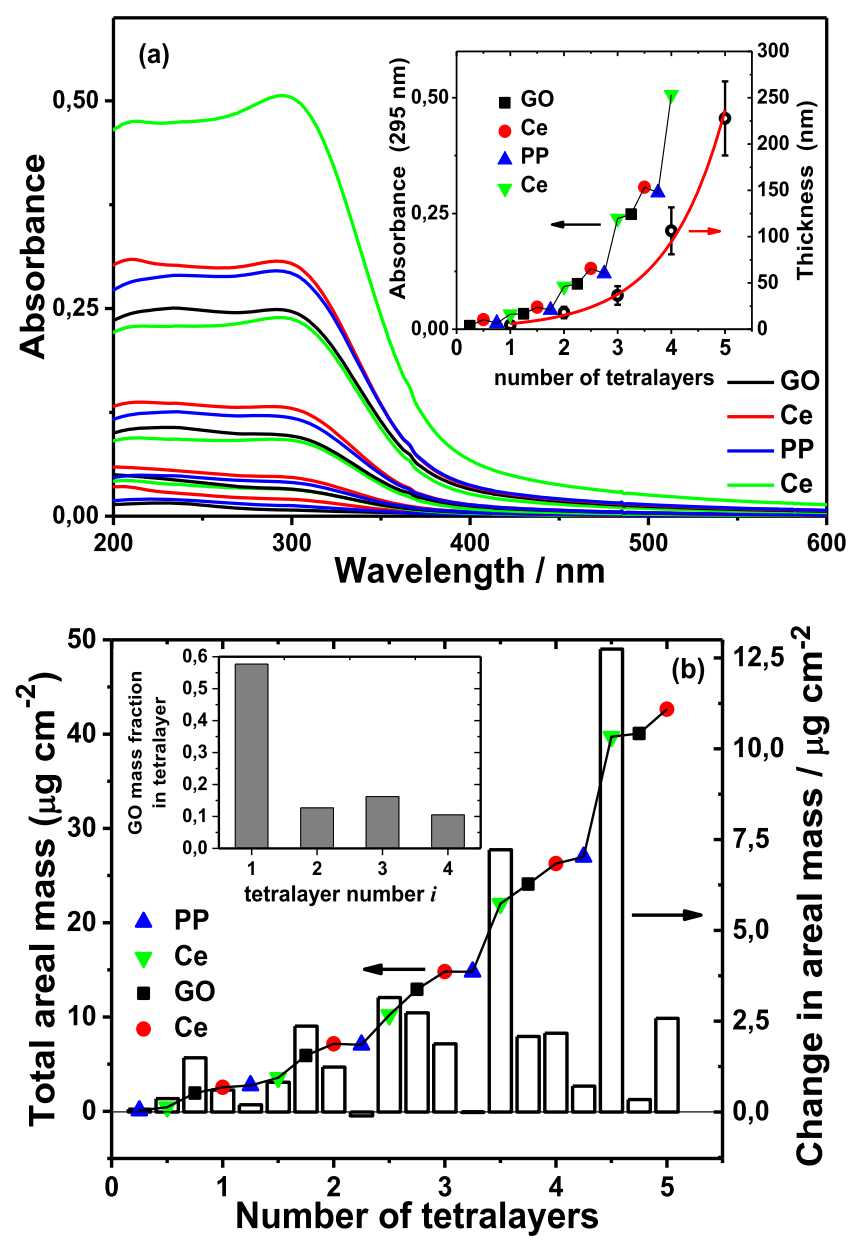

Figure 3. Growth of the $(\mathrm{GO} / \mathrm{Ce} / \mathrm{PP} / \mathrm{Ce})_{n}(n=0.25-5)$ multilayer. (a) Spectral changes upon deposition on one wall of a quartz cuvette (first layer GO). The inset shows the absorbance (solid line is a guide to the eye only) as a function of the number of tetralayers and the thickness of the dry film (on $\mathrm{Si}$ ) determined by AFM (error bars represent standard deviations of at least 20 measurements, solid line is an exponential fit to data); (b) film mass changes during the deposition process on a Au-plated QCR (first layer PP). Red and green symbols indicate a Ce layer after GO and PP, respectively (solid line is a guide to the eye). The inset shows the mass fraction of GO in the $i$ th tetralayer.

mass increase followed the PP layer adsorption. Deposition of Ce on top of a PP layer results in a higher mass increase than its deposition on a GO layer, which can be attributed to a higher amount of ionized groups in a PP layer. The mass detected by the QCR includes also hydration water in the film, and it is not possible to unambiguously estimate the amount of any single component. However, the polymerization experiments discussed later show an improved oxidation capacity of the $(\mathrm{PP} / \mathrm{Ce} / \mathrm{GO} / \mathrm{Ce})$ multilayers, proving an increased oxidant content. On the other hand, the contribution of GO to the film mass is highest in the two first tetralayers but decreases significantly after that. PP, with no absorbance or scattering effect in this spectral range, decreases the film absorbance (Figures 3a and S12), and the mass change upon a PP layer deposition is very small or even negative. This verifies the previous conclusion that it removes part of the previously deposited film, which is also seen in the mass density changes as a function of time (Figure S17). This kind of behavior is well-known with polyelectrolyte multilayers prepared by dip-
LbL, especially when the components are rather different from each other. ${ }^{57}$ The effect of water rinsing after the layer adsorption is small in all cases (Figure S17). It is interesting to note that the estimated density of the film is quite high and shows a decrease from ca. $6 \mathrm{~g} \mathrm{~cm}^{-3}$ (close to that of $\mathrm{Ce}$ ) to ca. $1.8 \mathrm{~g} \mathrm{~cm}^{-3}$ (close to that of GO) when the number of tetralayers increases from 1 to 5 (Figure S18). However, although the trend in density is clear, the actual values should be viewed with great care because they depend on measurements of samples on different substrates and using the film thickness of dry films and the areal mass density of hydrated films.

The composition of the $(\mathrm{GO} / \mathrm{Ce} / \mathrm{PP} / \mathrm{Ce})$ multilayers is important for their properties, but direct information about the amount of different components in the film is difficult to obtain. The absorption maximum of $\mathrm{Ce}(\mathrm{IV})$ at ca. $300 \mathrm{~nm}$ overlaps with the shoulder of the GO spectrum, but the main absorbance maximum of GO is at $230 \mathrm{~nm}$. Unfortunately, the ratio of these two GO bands depends on the aggregation of the GO platelets (Figures S6 and S7) because the $230 \mathrm{~nm}$ band corresponds to a $\pi \rightarrow \pi^{*}$ transition, while the other one is attributed to the attached carboxylate groups. ${ }^{58}$ However, above ca. $250 \mathrm{~nm}$, the effect of aggregation is insignificant, and in this range, we can use the mass absorption coefficient of an aqueous $\mathrm{GO}$ dispersion to analyze the film composition. In this analysis, we describe the $(\mathrm{GO} / \mathrm{Ce} / \mathrm{PP} / \mathrm{Ce})$ multilayer as being composed of the $\mathrm{GO}$ and $\mathrm{Ce} / \mathrm{PP} / \mathrm{Ce}$ strata using the estimated mass absorptivity of the $i$ th $\mathrm{Ce} / \mathrm{PP} / \mathrm{Ce}$ sequence units (see the Supporting Information for details). The calculated mass absorptivity for the $\mathrm{Ce} / \mathrm{PP} / \mathrm{Ce}$ sequence decreases with the stratum number, showing a change upon the transition from the exponential to the linear growth regime (Figure S10). This can be attributed to the higher hydration in thicker films, and it necessitates the use of a different mass absorptivity at different positions of the film in the analysis of the growth of the (GO/ $\mathrm{Ce} / \mathrm{PP} / \mathrm{Ce}$ ) multilayers. The effect of scattering (in addition to that possibly present in the spectrum of the GO dispersion) can be assumed to be small because the addition of GO brings about only small changes in the spectra. This conclusion is further supported by the good agreement between the observed and calculated film spectra (Figure S11). The obtained mass fractions $m_{\mathrm{GO}}^{(i)}$ of $\mathrm{GO}$ in the $i$ th tetralayer $\left(m_{\mathrm{GO}}^{(i)} / m_{\mathrm{obs}, \text { tot }}^{(i)}\right.$ where $m_{\mathrm{obs}, \text { tot }}^{(i)}$ is the observed mass of the $i$ th tetralayer) of the $(\mathrm{GO} / \mathrm{Ce} / \mathrm{PP} / \mathrm{Ce})$ multilayer are shown in the inset of Figure $3 \mathrm{~b}$. Initially, GO is the major component, but its mass fraction rapidly falls to ca. $0.1-0.15$ in the tetralayers, indicating that $\mathrm{Ce}$ and $\mathrm{PP}$ are the major components in thicker $(\mathrm{GO} / \mathrm{Ce} / \mathrm{PP} / \mathrm{Ce})$ films. However, the $\mathrm{GO}$ fraction is well above the reported percolation threshold values, which suggests that the GO sheets form a continuous support structure within the films. Comparison of the (PP/ $\mathrm{Ce})_{10}$ and $(\mathrm{PP} / \mathrm{Ce} / \mathrm{GO} / \mathrm{Ce})_{5}$ multilayers, which both contain the same number of $\mathrm{Ce}$ layers, shows that replacing every second PP layer with GO leads to an approximately twofold increase in the areal mass density. Interestingly, LbL multilayers could also be obtained from GO and cerium(IV) only, but the optical thickness of these films was only 5-10\% of the $\mathrm{GO} / \mathrm{Ce} / \mathrm{PP} / \mathrm{Ce}$ multilayers containing the same number of GO and Ce layers (Figure S13), probably because of the effective barrier formed by the GO layers in this case. Therefore, it is the combination of the GO and PP layers that gives rise to the enhanced growth. 

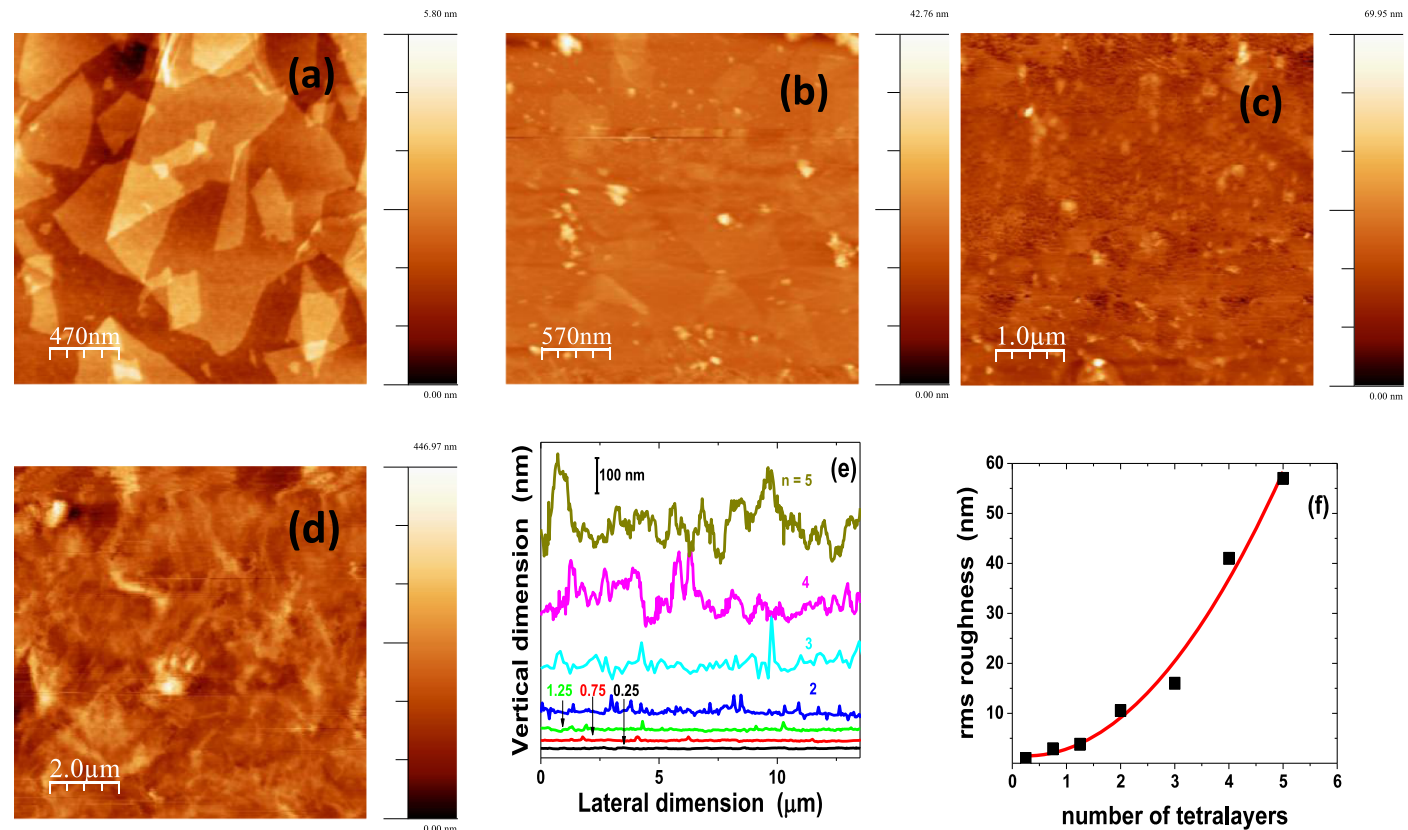

Figure 4. AFM images of thin multilayers (number of tetralayers in parenthesis, note different scales in figures; the $10 \times 10 \mu \mathrm{m}^{2}$ images of all films shown in the Supporting Information). (a) Si/GO ( $n=0.25)$; (b) Si/GO/Ce/PP $(n=0.75)$; (c) Si/(GO/Ce/PP/Ce)/GO ( $n=1.25)$; (d) Si/ $(\mathrm{GO} / \mathrm{Ce} / \mathrm{PP} / \mathrm{Ce})_{4}(n=4)$; (e) surface height profiles of the $10 \times 10 \mu \mathrm{m}^{2}$ images (from corner to corner) of films with different numbers of tetralayers (from below $0.25,0.75,1.25,2,3,4$, and 5 ); the curves are vertically shifted for clarity; (f) the evolution of the rms surface roughness as a function of the number of tetralayers; the line is a guide to the eye, representing a second-order fit to data.

According to the XPS analysis, the GO sample used in this work can be described by a formula $\mathrm{C}_{2.25} \mathrm{O}$, neglecting hydrogen and any small impurities. ${ }^{59}$ This $\mathrm{C} / \mathrm{O}$ atomic ratio is well in accordance with other reports of GO prepared similarly ${ }^{60}$ In this case, one hexagon in the GO lattice corresponds to the formula $\mathrm{C}_{2} \mathrm{O}_{0.89}$. Using the areal mass densities of GO in different tetralayers, obtained from the analysis above, we can estimate that there are ca. 28, 11, 36, and $68 \mathrm{nmol} \mathrm{cm}^{-2}$ of hexagons in the first, second, third, and fourth tetralayer, respectively. Therefore, even though the GO mass fraction decreases beyond the first tetralayer, its absolute amount increases from the second tetralayer onward. All the results suggest that substrate effects die out after the first tetralayer, that is, the zone I is more or less limited to this region of the film. GO does not have a well-defined twodimensional lattice but, using the hexagon area of the graphene lattice (ca. $0.05 \mathrm{~nm}^{2}$ ), we can estimate the GO (hexagon) coverages to be $1-2$ orders of magnitude above the monolayer coverage. Unfortunately, there is no reliable way to estimate the relative amounts of phosphate and Ce (and hydration water) in the film, but their combined mass exceeds that of GO. In the $(\mathrm{PP} / \mathrm{Ce})$ multilayers, the XPS spectra indicated a $\mathrm{Ce} / \mathrm{P}$ atomic ratio of $4.5: 1$, much higher than in cerium phosphates, ${ }^{61}$ suggesting the incorporation of free $\mathrm{Ce}(\mathrm{IV})$ aqua ions in the film. ${ }^{38}$ This was supported by the Ce $3 \mathrm{~d}$ spectra, which showed the presence of $\mathrm{CeO}_{2}$ in the dried film. Therefore, it is reasonable to assume that there are unbound cerium ions also in the $(\mathrm{GO} / \mathrm{Ce} / \mathrm{PP} / \mathrm{Ce})$ multilayers, in spite of cerium atoms binding to the oxygen-bearing functional groups in the GO sheets. The aqua complexes also account for the mobility of the cerium ions postulated previously but, ${ }^{38}$ in the three-component multilayers, the GO sheets may partially block their diffusion.

The AFM images of the surface morphology of the (GO/ $\mathrm{Ce} / \mathrm{PP} / \mathrm{Ce}$ ) films are shown in Figure 4 (see also S14 and
S15). The GO platelets adsorbed on an aminosilanized silicon wafer (Figure 4a) are lying flat on the surface but may be covered by other sheets (notice that the topmost sheet is actually folded). The thickness of the individual sheets is ca. $1.1 \mathrm{~nm}$, which indicates that they represent predominantly monolayer GO. ${ }^{51,53,62,63}$ The addition of Ce and PP layers softens the contours of the GO sheets, but they are still visible with ca. 1-2 nm edges. However, in thicker films, the GO sheets are no longer visible, and the film surface becomes very rugged. The root-mean-square (rms) surface roughness (measured from the $10 \mu \mathrm{m} \times 10 \mu \mathrm{m}$ AFM images) rapidly increases with the number of tetralayers $(n)$, and the height differences on the surface increase from few nanometers $(n=$ 0.75 and 1.25 ) to several tens of nanometers (Figure $4 \mathrm{e}, \mathrm{f}$ ). This is completely different from $(\mathrm{PP} / \mathrm{Ce})$ multilayers, which displayed a smooth globular morphology with roughness values of the order of $1 \mathrm{~nm}^{38}$ This suggests that the $(\mathrm{GO} / \mathrm{Ce} /$ $\mathrm{PP} / \mathrm{Ce}$ ) multilayers are not stratified structures but resemble composite materials with a random orientation of the GO sheets after the initial tetralayers. On the other hand, in a thin film, the adsorbed outer GO layer effectively masks the underlying layers, as only a weak P 2p band (at $134 \mathrm{eV}$ ) and no Ce 3d signals (at $880-920 \mathrm{eV}$ ) are observed in the XPS spectrum (Figure S16), which supports its role as a barrier.

Mechanical Properties of (PP/Ce/GO/Ce) Films. In order to study the mechanical properties of the threecomponent multilayers, the automatic LbL-QCR system was used to grow a 40 tetralayer thick $(\mathrm{PP} / \mathrm{Ce} / \mathrm{GO} / \mathrm{Ce})$ multilayer and characterize its mechanical properties in situ. The areal mass density of the film (Figure S19), calculated from eq 1, shows an initial exponential growth during the 4-5 tetralayers with $\mathrm{Ce}$ as the major component, similar to Figure $3 \mathrm{~b}$. After that, the growth slows down and seems to attain a maximum after ca. 10 tetralayers. However, eq 1 is a first-order approximation that holds only for relatively thin films and is 
not valid with these thick multilayers. After ca. 10 tetralayers, the imaginary part of the surface acoustic impedance reaches a maximum, which is followed by a series of minima and maxima. The same happens also with the real part (Figure S20). These extremes represent acoustic film resonances and indicate that the film thickness has reached the quarter of the wavelength of the shear wave in the material. ${ }^{49}$ The maxima are repeated approximately at every odd multiple of the quarter wavelength, until the wave is finally attenuated. It is noteworthy that over 150 bilayers are required to reach acoustic film resonance with poly(styrene sulfonate) (PSS)/ poly(diallyl dimethylammonium) (PDADMA) (see Table 1 for the acronyms) multilayers. ${ }^{10,33}$

Table 1. Estimated Complex Shear Moduli and Loss Angle of Some LbL Multilayers (at $10 \mathrm{MHz})^{a}$

\begin{tabular}{llll}
\multicolumn{1}{c}{ multilayer } & $G^{\prime}(\mathrm{MPa})$ & $G^{\prime \prime}(\mathrm{MPa})$ & $\delta(\mathrm{deg})$ \\
$\mathrm{PSS} / \mathrm{PDADMA}^{b, e}$ & 130 & 70 & 27 \\
$\mathrm{CHI} / \mathrm{HA}^{c, e}$ & 1.7 & 2.4 & 55 \\
$\mathrm{PAH} / \mathrm{HA}^{c, e}$ & 1.0 & 1.4 & 55 \\
$\mathrm{CHI} / \mathrm{HA} / \mathrm{CHI} / \mathrm{PAA}^{c, e}$ & 156 & 51 & 18 \\
$\mathrm{PP} / \mathrm{Ce}{ }^{d, f}$ & 9 & 9 & 47 \\
$\mathrm{PP} / \mathrm{Ce} / \mathrm{GO} / \mathrm{Ce}^{f, g}$ & $22(20)^{h}$ & $9(1)^{h}$ & $22(2)^{h}$
\end{tabular}

${ }^{a}$ Acronyms: PSS, poly(styrene sulfonate); PDADMA, poly(diallyl dimethylammonium); $\mathrm{CHI}$, chitosan; HA; hyaluronic acid; $\mathrm{PAH}$, poly(allyl amine); PAA, poly(acrylic acid). ${ }^{b}$ From ref $33 .{ }^{c}$ Based on data in refs 35 and $49 .{ }^{d}$ Based on data in ref $38 .{ }^{e}$ Calculated using density of $1200 \mathrm{~kg} \mathrm{~m}^{-3} \cdot{ }^{f_{\text {Using density }}}$ of $1500 \mathrm{~kg} \mathrm{~m}^{-3} \cdot{ }^{g_{ \pm}} \mathrm{MPa}$. ${ }^{h}$ PP-terminated film.

A more informative figure is obtained by plotting the imaginary part of the surface acoustic impedance as a function of its real part in the form of an Argand diagram (Figure 5). The diagram depicts an impedance spiral, which should converge at a point corresponding to the bulk acoustic impedance of the film material. ${ }^{49}$ This point lies on the polar line, which extends from origo to the vertical tangential point of the spiral and forms an angle $\delta / 2$ with the real axis, $\delta$ being the loss angle $\left(\tan \delta=G^{\prime \prime} / G^{\prime}\right)$. The fit of the acoustic

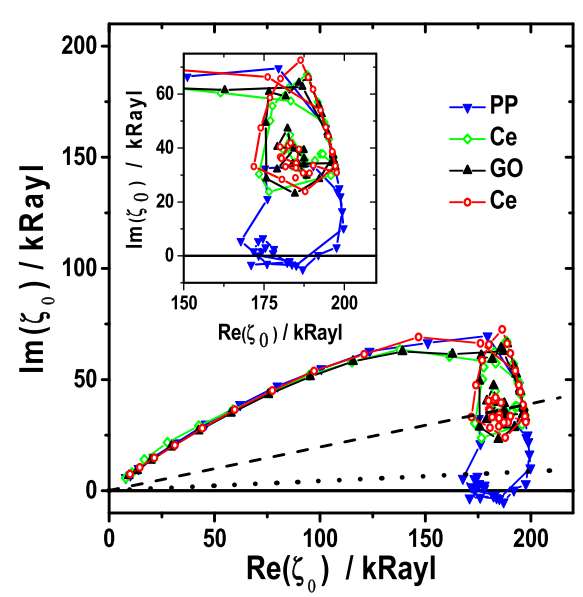

Figure 5. Argand diagram of the real and imaginary parts of the acoustic impedance during the fabrication of a $(\mathrm{PP} / \mathrm{Ce} / \mathrm{GO} / \mathrm{Ce})_{40}$ multilayer (first layer PP). The inset shows a close-up of the spiral section. Color coding refers to the terminating layer as in Figure 3. Approximate polar lines are drawn for the Ce- or GO-terminated and for the PP-terminated films (dashed and dotted line, respectively). impedance data to the mathematical model previously presented should yield the mechanical properties of the film.

However, the diagram in Figure 5 presents some strange features when compared to those obtained with other multilayers. Depending on the terminating layer, data form several spirals. Those corresponding to $\mathrm{Ce}$ or GO as the outermost layer are, however, superimposed within experimental error, but with PP as the terminating layer, the curve clearly deviates from others. Two separate spirals without a common convergence point suggest that exponential growth with effective in-film diffusion continues still in these thick films, and the nature of the whole film depends on the last layer. ${ }^{49}$ However, the slope of the curve before the imaginary maximum is extraordinarily low, ${ }^{49}$ and fitting data to the theoretical model has not been successful. The theory assumes that the properties of the film bulk remain unchanged during the build-up process. The analysis presented above suggests that the film structure and composition change with thickness, and we attribute the deviation from the theory to these changes. In spite of this, the surface acoustic impedance $Z_{\mathrm{f}}$ should approach the bulk acoustic impedance of the film material when the thickness increases and is given by the convergence point of the impedance spiral. Both spirals in Figure 5 tend to converge to values, which can be used to estimate $Z_{\mathrm{f}}$. It is related to the film density and its complex shear modulus by a simple eq 2

$$
Z_{\mathrm{f}}=\left(\rho_{\mathrm{f}} G_{\mathrm{f}}\right)^{1 / 2}
$$

Some common polyelectrolyte multilayers studied using surface acoustic impedance yield modulus values for comparison (Table 1). The complex shear modulus of a PSS/PDADMA (see Table 1 for the acronyms here and below) multilayer indicates a rather stiff $(|G| \approx 150 \mathrm{MPa})$ and elastic $\left(G^{\prime} \gg G^{\prime \prime}\right)$ film. ${ }^{33}$ On the other hand, (CHI/HA) and (PAH/HA) multilayers are much softer with the shear moduli of ca. $|G| \approx 2.8 \mathrm{MPa}$ and $|G| \approx 1.7 \mathrm{MPa}$, respectively, and more viscous $\left(G^{\prime}<G^{\prime \prime}\right){ }^{35,49}$ The low magnitude of the shear moduli, together with high loss moduli and, consequently, a loss angle above $45^{\circ}$, indicate hydrogel-like films. In fact, the $\mathrm{CHI} / \mathrm{HA}$ and $\mathrm{PAH} / \mathrm{HA}$ films exhibit fully exponential growth because the polycation in both multilayers can diffuse deep into the film. ${ }^{35}$ Interestingly, replacing every second HA layer with PAA greatly increases the stiffness $(|G| \approx 164 \mathrm{MPa})$ and elasticity $\left(G^{\prime} \gg G^{\prime \prime}\right)$ of ( $\left.\mathrm{CHI} / \mathrm{HA}\right)$ multilayers (the moduli values given refer specifically to zone II in this case; zone III is always much softer and more viscous), which was attributed to the cross-linking of the CHI chains by PAA. For the (PP/Ce/ $\mathrm{GO} / \mathrm{Ce}$ ) multilayer, when either $\mathrm{GO}$ or $\mathrm{Ce}$ is the terminating layer, the bulk acoustic impedance can be estimated to be ca. $Z_{\mathrm{f}}$ $\approx(184 \pm 3) \mathrm{kRayl}+\mathrm{j}(35 \pm 3) \mathrm{kRayl}$. Assuming the density of the film to be higher, ca. $1500 \mathrm{~kg} \mathrm{~m}^{-3}$ in this case, leads to a shear modulus of $|G| \approx 24 \mathrm{MPa}$ with $G^{\prime} \gg G^{\prime \prime}$, representing a relatively soft elastic film. On the other hand, the Argand spiral for the PP terminated films suggests a shear modulus of ca. $|G|$ $\approx 20 \mathrm{MPa}$ and $G^{\prime} \gg G^{\prime \prime} \approx 0$, that is, representing an almost pure soft elastomer. This implies that the Young's moduli of these films are of the order of $60-70 \mathrm{MPa}$, assuming the films to be isotropic and nearly purely elastic. By comparison, for $(\mathrm{PP} / \mathrm{Ce})$ multilayers, we obtain from previous results (assuming film density of $1500 \mathrm{~kg} \mathrm{~m}^{-3}$ ) 38 a shear modulus of $|G| \approx 13 \mathrm{MPa}$ and $G^{\prime} \approx G^{\prime \prime}$, which represents a soft elastic material with a viscous nature resembling that of the 

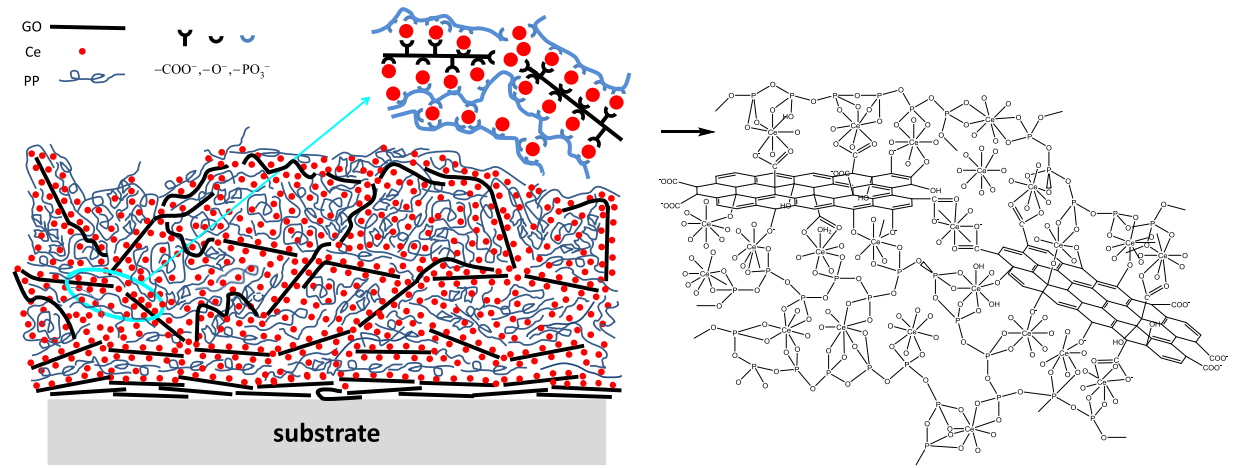

Figure 6. Schematic presentation of a $(\mathrm{GO} / \mathrm{Ce} / \mathrm{PP} / \mathrm{Ce})$ multilayer (PP-terminated), the gradual evolution of roughness, and the suggested bonding scheme within the film. No attempt is made to show the actual PP chain length, GO sheet size or 3D structure; in the Ce coordination sphere (assumed coordination number $=8$ ) $\mathrm{O}$ represents any oxygen-containing ligand (water, $-\mathrm{O}^{-},-\mathrm{P}-\mathrm{O}, \mathrm{COO}$ ).

multilayers prepared from biological polyelectrolytes. Therefore, the behavior of the $(\mathrm{PP} / \mathrm{Ce})$ and $(\mathrm{GO} / \mathrm{Ce} / \mathrm{PP} / \mathrm{Ce})$ films is analogous to that of the (CHI/HA) and ( $\mathrm{CHI} / \mathrm{HA} / \mathrm{CHI} /$ PAA) multilayers, although the effect is much larger in the latter case, probably because of a better intermixing of the components.

Most LbL films rely on electrostatic interactions between the components. ${ }^{1-3}$ However, inorganic PP is a biomolecule that can be cross-linked by metal cations, as it forms strong complexes, especially with transition metals. ${ }^{64,65}$ Cross-linking by reversible metal-ligand coordination bonds stiffens polymeric materials but leaves them relatively soft. ${ }^{66} \mathrm{An}$ important example concerns the stiffening of catecholcontaining polymers and peptides by $\mathrm{Fe}$ (III)-mediated crosslinking. ${ }^{67,68}$ Adsorption of metal ions on GO has been shown to take place preferentially by an entropy-driven complex formation between metals and the surface carboxylate and hydroxyl groups. ${ }^{69,70}$ The addition of complexing metal ions in a GO paper substantially improves its mechanical properties by cross-linking the GO sheets together. ${ }^{71}$ Analysis of a GO-Zrphosphate nanocomposite shows that the metal forms complexes with the phosphate anion and the oxygen groups on GO, and the phosphate can further bind metals from solution. ${ }^{72}$ Specifically, cerium forms complexes on oxygenbearing functionalities on the $\mathrm{GO}$ surface in $\mathrm{GO}-\mathrm{CeO}_{2}$ composites. $^{73}$ These results support the conclusion that the $(\mathrm{GO} / \mathrm{Ce} / \mathrm{PP} / \mathrm{Ce})$ and $(\mathrm{PP} / \mathrm{Ce})$ multilayers are based on complex formation, that is, coordination bonds between various oxygen ligands and $\mathrm{Ce}(\mathrm{IV})$ ions. An important property of such flexible transition-metal coordination networks is their ability to self-assemble and tend toward an equilibrium structure. The $(\mathrm{PP} / \mathrm{Ce})$ films represent such coordinatively cross-linked polymers, which try to minimize their surface, remain soft and exhibit high losses, but are strengthened because of cross-linking. In general, the viscoelastic behavior is dependent on the experimental time scale. In the frequency range of the $\mathrm{QCR}$, the viscous nature must be attributed to the PP chain deformations because the time scale of coordinative rearrangement is in the millisecond range or above. ${ }^{68}$

The GO sheets do not form lamellar layers within the (GO/ $\mathrm{Ce} / \mathrm{PP} / \mathrm{Ce}$ ) multilayers but appear to be randomly oriented, forming a network of platelets in the $\mathrm{PP} / \mathrm{Ce}$ matrix. The mechanical consequences of an analogous behavior have been observed in many different cases. The collageneous tissue in the sea cucumber dermis contains collagen fibrils, which can link together and increase the stiffness and elasticity of the tissue. ${ }^{74}$ An artificial analogue imitating the biomaterial has been prepared using rubbery polymer and cellulose nanofibers, in which hydration controls the interfiber interactions and, thereby, the stiffness of the composite. ${ }^{75}$ In the LbL films prepared from rigid cellulose nanocrystals and GO sheets, the advantageous mechanical properties of both components could be combined. ${ }^{63}$ A small increase in film stiffness was observed also with PEI/PAA films when every second PAA layer was substituted for a MTM platelet layer. ${ }^{19}$ On the other hand, substitution of every second PSS layer for GO in (PAH/PSS) multilayers significantly improved their elastic modulus and produced very smooth films. ${ }^{53}$ Similarly, introducing GO by means of the Langmuir-Blodgett technique in PAH/PSS multilayers increased their Young's modulus. ${ }^{51}$ GO sheets significantly stiffen polymer nanocomposites already at a low weight fraction, and the percolation threshold for randomly oriented sheets is quite low. ${ }^{24,28,29}$

Summarizing, the $(\mathrm{GO} / \mathrm{Ce} / \mathrm{PP} / \mathrm{Ce})$ multilayer can be regarded as a $(\mathrm{PP} / \mathrm{Ce})$ matrix reinforced with randomly deposited GO sheets (Figure 6). The replacement of every second PP layer with GO influences mainly the film elasticity, approximately doubling the storage modulus, while the loss modulus is unaffected. The mechanical energy losses in both types of multilayers must be attributed to the $\mathrm{PP} / \mathrm{Ce}$ matrix, but the network of strong elastic GO sheets increases the elasticity of the film. On the other hand, PP termination in (PP/Ce/GO/Ce) multilayers almost totally removes mechanical losses without markedly affecting the elasticity. The moduli of the $(\mathrm{GO} / \mathrm{Ce} / \mathrm{PP} / \mathrm{Ce})$ multilayer are similar to those of metallopolymer films above their glass transition temperature. ${ }^{76}$ We tentatively attribute the diminished losses in the PP-terminated films to two factors. First, PP removes loosely bound material from the film surface, thereby decreasing the viscous drag at the film-solution interface. Second, PP chains probably can diffuse into the film, binding free $\mathrm{Ce}(\mathrm{IV})$ ions, filling holes, covering the sheets, and expelling water, thereby stiffening the $\mathrm{PP} / \mathrm{Ce}$ matrix. The GO/Ce bicomponent films were not stable and could be rinsed away from the surface, showing them to be quite brittle, but in the three-component films, PP glues the components together. Upon deformation, the GO sheet network bound to the $\mathrm{PP} / \mathrm{Ce}$ matrix acts as a spring system, which stores elastic energy. As the film grows the randomness of the GO deposition morphology increases after every tetralayer, which also leads to a very rough surface morphology. As the $(\mathrm{PP} / \mathrm{Ce})$ films are very smooth, this 

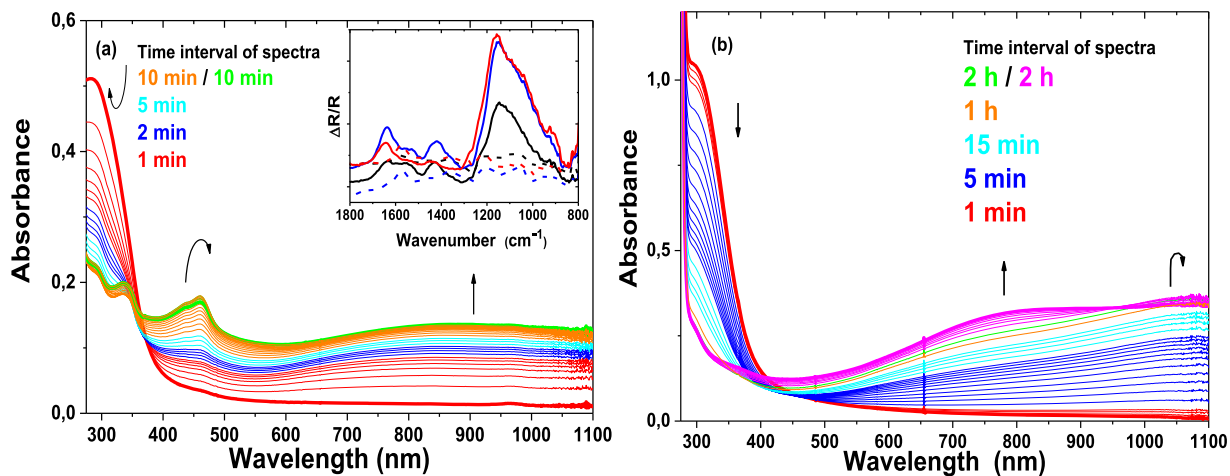

Figure 7. Polymerization of (a) $10 \mathrm{mM}$ Py and (b) $10 \mathrm{mM}$ EDOT on a $(\mathrm{GO} / \mathrm{Ce} / \mathrm{PP} / \mathrm{Ce})_{4}$ multilayer on the walls of a quartz cuvette at $\mathrm{pH} 1.5$. The color-coding of the time interval between the spectra shown (two colors indicate change reversal), and the first and the last spectra are shown with thicker lines; total reaction time was $3 \mathrm{~h}$ in (a) and $17.5 \mathrm{~h}$ in (b). The inset in (a) shows the PM-IRRAS spectra of the (GO/Ce/PP/Ce) ${ }_{n} \mathrm{GO}$ films with $n=2$ (black lines) or $n=4)$ (blue) and (PP/Ce) ${ }_{4}$ (red) films before (solid lines) and after (dashed lines) Py polymerization.

roughening must be attributed to the disorientation, aggregation, crumpling, and folding of the GO sheets during the assembly process. ${ }^{51}$ Several studies report smooth polyelectrolyte-GO multilayers with an average roughness of ca. $10-20 \%$ of the average film thickness, compared to ca. $25 \%$ in the case of a $(\mathrm{GO} / \mathrm{Ce} / \mathrm{PP} / \mathrm{Ce})_{5}$ film..$^{25-27,53}$ However, these films are either very thin or have been dried with a gas flow between the deposition of the layers. We attribute the difference to the mechanical effect of drying as the polyelectrolyte multilayers based on electrostatic interactions are kinetically locked unless annealed by a high salt concentration. ${ }^{77,78} \mathrm{We}$ suggest that the reversible nature of metal coordination in our films manifests itself during the PP (and Ce) deposition, leading to smooth (PP/Ce) films and to the PP-termination effect in the $(\mathrm{GO} / \mathrm{Ce} / \mathrm{PP} / \mathrm{Ce})$ multilayers, but the GO sheets are too massive for a noticeable effect in the deposition time scale.

Polymerization of Py and EDOT. We have previously shown that both monomers, Py and EDOT, can be electrolessly polymerized on Ce/PP multilayers immersed in the monomer solutions, and we have presented a thorough kinetic analysis of the process. ${ }^{38,39}$ The polymerization is coupled to the reduction of $\mathrm{Ce}(\mathrm{IV})$ to $\mathrm{Ce}(\mathrm{III})$ in the film, which can be followed at ca. $300 \mathrm{~nm}$, and both processes obey pseudo-first order kinetics on (PP/Ce) multilayers. However, the formation of polyPy takes place much faster than that of PEDOT because of the high oxidation potential of the EDOT monomer. The process is self-limited and ends when all oxidant in the film is consumed.

The oxidizing capacity of ( $\mathrm{PP} / \mathrm{Ce} / \mathrm{GO} / \mathrm{CE})$ multilayers was studied under similar conditions as in our earlier paper. ${ }^{39}$ The effective oxidizing potential of a $(\mathrm{PP} / \mathrm{Ce} / \mathrm{GO} / \mathrm{PP}) / \mathrm{Ce}$ film at $\mathrm{pH} 1.5$ was initially $1.1 \mathrm{~V}$ versus sodium saturated calomel electrode and leveled at a value of ca. $0.9 \mathrm{~V}$, in good accordance with previous results, which shows that GO does not affect the oxidizing power of the films. Upon exposure to an acidic monomer solution (Py or EDOT), the absorbance decreases at around $300 \mathrm{~nm}$ and increases above $400 \mathrm{~nm}$ (Figure 7). The decrease is due to the reduction of $\mathrm{Ce}(\mathrm{IV})$ in the film and, at the same time, a polyPy or PEDOT film is formed on the multilayer in an oxidized state. The film attached strongly to the multilayer and is not washed away upon rinsing the cuvette. On the other hand, a $(\mathrm{GO} / \mathrm{Ce})_{7}$ multilayer could also polymerize $\mathrm{Py}$, but both polyPy and the oxidative multilayer were removed upon rinsing (Figures S21 and S22). Cerium probably reduces the interactions between the GO sheets because the LbL films prepared from GO only are robust. $^{79}$

The $(\mathrm{PP} / \mathrm{Ce} / \mathrm{GO} / \mathrm{Ce})_{4}$ film used in the polymerization experiments was considerably thicker (ca. $150 \mathrm{~nm}$ in a dry state) than the oxidative multilayers used earlier. However, also in this case, practically all Ce(IV) in the film was consumed, as can be seen from the spectra taken after the polymerization (Figures S24 and S27). The reaction time was longer than with thinner $(\mathrm{PP} / \mathrm{Ce})$ multilayers, requiring $3 \mathrm{~h}$ for Py and nearly $20 \mathrm{~h}$ for EDOT, but the amount of the formed polymer was also higher. The comparison with the spectra obtained using $(\mathrm{PP} / \mathrm{Ce})_{5}$ films showed that the four-tetralayer thick threecomponent film produced approximately twice the amount of polyPy and 4 times more PEDOT, that is, an increase of 25$150 \%$ per a nominal Ce-layer. The amount of active Ce(IV) in the film also increased by the factor of 3-6 (estimated from the absorbance change at $300 \mathrm{~nm}$ ). The PM-IRRAS spectra of the $(\mathrm{GO} / \mathrm{Ce} / \mathrm{PP} / \mathrm{Ce})_{n=2,4} \mathrm{GO}$ and $(\mathrm{PP} / \mathrm{Ce})_{4}$ films are shown in the inset of Figure $7 \mathrm{a}$ before and after the Py polymerization. Before the polymerization, the spectra are dominated by an unresolved wide band at $900-1300 \mathrm{~cm}^{-1}$. This range contains several phosphate group vibrations, for example, the $\nu_{\mathrm{as}, \mathrm{POP}}$ (1023 and $\left.1110 \mathrm{~cm}^{-1}\right), \nu_{\mathrm{as}, \mathrm{PO}_{3}}$, and $\nu_{\mathrm{P}=\mathrm{O}}\left(1250-1300 \mathrm{~cm}^{-1}\right)$ stretching bands. ${ }^{80,81}$ In addition, GO has several bands in this range, but the comparison of the spectra with and without GO shows that PP must be the main contributor in this range (the intensity is also proportional to the number of the PP layers in the film), together with some bands due to the Ce complexes. The bands at 1636 and $1420 \mathrm{~cm}^{-1}$ can be assigned to the $\mathrm{C}=$ $\mathrm{C}$ and $\mathrm{C}=\mathrm{O}$ stretching or $\mathrm{C}-\mathrm{O}$ deformation in $\mathrm{GO}$, respectively. ${ }^{26,69,82}$ In all cases, these bands disappear after the Py polymerization, and a small band assigned to the $\mathrm{C}=\mathrm{C}$ stretching in the Py ring appears at $1573 \mathrm{~cm}^{-1,83,84}$ which implies the formation of a uniform and thick polyPy film. Therefore, these thick oxidative layers are effective platforms for the electroless production of relatively thick conducting polymer films.

The kinetics of the Ce(IV) reduction, which is the primary redox reaction, and that of the subsequent polymerization reaction, were followed at 300 and $800 \mathrm{~nm}$, respectively. Contrary to the previous results with thin films, the absorbance-time curves could not be well fitted by a simple pseudo-first order reaction but required two exponential terms (see Figures S25 and S28), and the resulting kinetic data are 
shown in Table 2. The first and second primary rate constants (measured at $300 \mathrm{~nm}$ ) are higher than the polymerization

Table 2. Apparent Pseudo-First-Order Rate Constants Calculated from the Absorbance Changes at 300 and 800 $\mathrm{nm}$ in Py and EDOT Polymerization ${ }^{a}$

$\begin{array}{lcc} & k_{\text {app }, 1}(300 \mathrm{~nm}) / 10^{-4} \mathrm{~s}^{-1} & k_{\mathrm{app}, 2}(800 \mathrm{~nm}) / 10^{-4} \mathrm{~s}^{-1} \\ \text { Py } & 83 \pm 2 & 60 \pm 2 \\ & 10.9 \pm 0.2 & 4.5 \pm 0.1 \\ \text { EDOT } & 7.2 \pm 0.4 & 3.34 \pm 0.05 \\ & 2.5 \pm 0.1 & 0.46 \pm 0.02\end{array}$

${ }^{a}$ Monomer concentrations $10 \mathrm{mM}, \mathrm{pH} 1.5$.

constants (measured at $800 \mathrm{~nm}$ ). The presence of two processes at both wavelengths, with time scales separated approximately by an order of magnitude, is an unexpected observation. Some indication of the nature of this process can be best obtained from the spectra obtained during the EDOT polymerization. The color-coded spectra at different stages of the process (Figure S26) reveal that there is a clear isosbestic point at ca. $460 \mathrm{~nm}$ up to approx. 30 minutes. After that, the point shifts toward lower wavelengths and later disappears. This implies that more than two chromophoric species [Ce(IV) and "oxidized PEDOT"] are present in the system. The spectra show that two peaks clearly emerge after a few hours at ca. 800 and $1100 \mathrm{~nm}$. These bands are well in accordance with the two highest energy polaron bands in oxidized PEDOT ${ }^{85}$ With time, the band at $1100 \mathrm{~nm}$ decreases, and only a slowly growing band at ca. 800 remains. This can be interpreted as the formation of the bipolaron-type charge carriers from the polarons, and it indicates an increase in the oxidation level of PEDOT. ${ }^{86}$ Therefore, the observed slower process corresponds to the further oxidation of the film after and simultaneously with the polymerization. This conclusion is supported by rate determination carried out at $950 \mathrm{~nm}$, where the contribution from the two polaron bands is small. At this wavelength, a single exponential growth fits the data much better (but not perfectly). Similarly, during the polyPy film formation, bands are observed at ca. 430, 460, and $870 \mathrm{~nm}$. They can be attributed to the band gap transition and the polaron and the bipolaron bands, respectively. ${ }^{87}$ This suggests that the polymer formation process is generally biphasic on these thick films. First, the oxidation of the monomer $M$ by $\mathrm{Ce}(\mathrm{IV})$ in the oxidative multilayer generates radical cations $\mathrm{M}^{+\bullet}$, which couple to form polymer with polarons in the chain

$$
x \mathrm{M} \stackrel{\mathrm{Ce}(\mathrm{IV})}{\longrightarrow} x \mathrm{M}^{+\bullet} \rightarrow \cdots \mathrm{P}^{+\bullet} \ldots
$$

This is the primary polymerization reaction. The secondary reaction involves the generation of bipolarons from polarons, either by the direct oxidation of polarons $\left(\mathrm{P}^{+\bullet} \stackrel{\mathrm{Ce}(\mathrm{IV})}{\longrightarrow} \mathrm{BP}^{2+}\right)$ or by the further formation of polarons in the neutral polymer chains and their subsequent disproportionation to bipolarons $\left(2 \mathrm{P}^{+\bullet} \rightleftharpoons \mathrm{BP}^{2+}+\mathrm{M}\right)$. The $\mathrm{Ce}(\mathrm{IV})$ consumption is also biphasic, which shows that primary polymerization loses importance at later stages. The rate constant of the second step is markedly lower at $800 \mathrm{~nm}$ (oxidized polymer) than at $300 \mathrm{~nm}$ (oxidant), which implies bipolaron formation mainly by the polaron coupling. In the previous study with thin films, it was concluded that the conducting polymer film can mediate electrons between the oxidant and monomers in solution. ${ }^{39}$ In (GO/Ce/PP/Ce) films, the insulating GO layers probably slow down this intrafilm charge transfer and also hamper the diffusion of $\mathrm{Ce}(\mathrm{IV})$ within the film (GO can be reduced to a conducting form in these films, but this work will be presented in a forthcoming paper).

\section{CONCLUSIONS}

LbL multilayers formed using a redox-active transition metal ion, for example, $\mathrm{Ce}(\mathrm{IV})$, and inorganic PP can be used as general oxidative platforms. Highly stable and rapidly growing oxidative $(\mathrm{GO} / \mathrm{Ce} / \mathrm{PP} / \mathrm{Ce})$ three-component films can be prepared by replacing every second $\mathrm{PP}$ layer with GO sheets in the $(\mathrm{PP} / \mathrm{Ce})$ films. The growth is initially exponential but levels off to a rapid linear growth after ca. 4-5 (GO/Ce/PP/ $\mathrm{Ce})$ tetralayers, and several hundred nanometer thick films can be obtained with only a few tetralayers. The composition and morphology of the films change with thickness. GO is the major component within the first tetralayer, but its mass fraction drops to $0.1-0.15$ in the subsequent tetralayers, and $\mathrm{Ce}$ and PP dominate in thick films. The surface roughness also increases considerably with thickness, and the GO sheets are randomly oriented in thick multilayers. Both the $(\mathrm{PP} / \mathrm{Ce})$ and $(\mathrm{GO} / \mathrm{Ce} / \mathrm{PP} / \mathrm{Ce})$ films are based on reversible metal coordination between $\mathrm{Ce}$ and the oxygen-containing ligand groups in PP and GO.

The mechanical properties of the three-component films are greatly modified by the incorporated GO. Compared to the (PP/Ce) films, the shear storage modulus, which describes the film elasticity, increases more than twofold, while the loss modulus, reflecting the viscous nature of the film, remains unchanged. However, there is a distinct terminating layer effect because the loss modulus is close to zero in the PP-terminated (GO/Ce/PP/Ce) films. The improved elasticity can be attributed to a continuous network of strong GO sheets in the film, while PP brings ductility in the structure. The (GO/ $\mathrm{Ce})$ multilayers without $\mathrm{PP}$ are very brittle.

The $(\mathrm{GO} / \mathrm{Ce} / \mathrm{PP} / \mathrm{Ce})$ multilayers contain more cerium per nominal Ce-layer than the $(\mathrm{PP} / \mathrm{Ce})$ films and can be used to electrolessly polymerize conducting polymer films on their surface. Consequently, the formed polymer films are thicker, but their formation is slower. Contrary to the $(\mathrm{PP} / \mathrm{Ce})$ films, the polymerization kinetics on $(\mathrm{GO} / \mathrm{Ce} / \mathrm{PP} / \mathrm{Ce})$ multilayers is biphasic, and the slower process is attributed to the increase of the oxidation level of the conducting polymer film.

\section{ASSOCIATED CONTENT}

\section{S Supporting Information}

The Supporting Information is available free of charge on the ACS Publications website at DOI: 10.1021/acs.langmuir.8b02784.

Experimental details, mass absorption coefficient of GO suspension, effect of aggregation on the GO spectrum, spectral and areal mass density changes during the (PP/ Ce) film build-up, time dependence of areal mass density during the (GO/Ce/PP/Ce) film build-up, description of the method for the film composition estimation, mass absorption coefficients of different $(\mathrm{Ce} / \mathrm{PP} / \mathrm{Ce})$ slices in $(\mathrm{PP} / \mathrm{Ce})$ films, observed and calculated spectral of different tetralayers in $(\mathrm{GO} / \mathrm{Ce} /$ $\mathrm{PP} / \mathrm{Ce}$ ) films, AFM images of (GO/Ce/PP/Ce) films, XPS survey spectrum, imaginary and real parts of surface acoustic impedance, spectra and kinetic fits of the 
polymerization of Py and EDOT, build-up of a (GO/ $\mathrm{Ce}$ ) film, and polymerization of Py (PDF)

\section{AUTHOR INFORMATION}

\section{Corresponding Authors}

*E-mail: mikko.salomaki@utu.fi (M.S.).

*E-mail: jukka.lukkari@utu.fi (J.L.).

\section{ORCID $\odot$}

Mikko Salomäki: 0000-0001-6190-2073

Jukka Lukkari: 0000-0002-9409-7995

\section{Present Address}

${ }^{\S}$ Laboratory of Physical Chemistry, Åbo Akademi University, Porthansgatan 3-5, FI-20500 Turku/Åbo, Finland.

\section{Funding}

J.Kauppila gratefully acknowledges funding from the Graduate School of Materials Research (GSMR, Finland).

\section{Notes}

The authors declare no competing financial interest.

\section{ACKNOWLEDGMENTS}

We gratefully thank Dr Jarkko Leiro for measuring the XPS spectra.

\section{REFERENCES}

(1) Multilayer Thin Films: Sequential Assembly of Nanocomposite Materials; Decher, G.; Schlenoff, J. B., Eds.; Wiley-VCH: Weinheim, Germany, 2012.

(2) Borges, J.; Mano, J. F. Molecular Interactions Driving the Layerby-Layer Assembly of Multilayers. Chem. Rev. 2014, 114, 8883-8942.

(3) Richardson, J. J.; Cui, J.; Björnmalm, M.; Braunger, J. A.; Ejima, H.; Caruso, F. Innovation in Layer-by-Layer Assembly. Chem. Rev. 2016, 116, 14828-14867.

(4) Ladam, G.; Schaad, P.; Voegel, J. C.; Schaaf, P.; Decher, G.; Cuisinier, F. In Situ Determination of the Structural Properties of Initially Deposited Polyelectrolyte Multilayers. Langmuir 2000, 16, $1249-1255$

(5) Li, Y.; Wang, X.; Sun, J. Layer-by-layer assembly for rapid fabrication of thick polymeric films. Chem. Soc. Rev. 2012, 41, 59986009

(6) Cho, J.; Char, K.; Hong, J.-D.; Lee, K.-B. Fabrication of Highly Ordered Multilayer Films Using a Spin Self-Assembly Method. Adv. Mater. 2001, 13, 1076-1078.

(7) Schaaf, P.; Voegel, J.-C.; Jierry, L.; Boulmedais, F. Spray-Assisted Polyelectrolyte Multilayer Buildup: from Step-by-Step to Single-Step Polyelectrolyte Film Constructions. Adv. Mater. 2012, 24, 10011016

(8) Salomäki, M.; Peltonen, T.; Kankare, J. Multilayer films by spraying on spinning surface - Best of both worlds. Thin Solid Films 2012, 520, 5550-5556

(9) Salomäki, M.; Tervasmäki, P.; Areva, S.; Kankare, J. The Hofmeister Anion Effect and the Growth of Polyelectrolyte Multilayers. Langmuir 2004, 20, 3679-3683.

(10) Salomäki, M.; Laiho, T.; Kankare, J. Counteranion-Controlled Properties of Polyelectrolyte Multilayers. Macromolecules 2004, 37, 9585-9590.

(11) Yoo, D.; Shiratori, S. S.; Rubner, M. F. Controlling Bilayer Composition and Surface Wettability of Sequentially Adsorbed Multilayers of Weak Polyelectrolytes. Macromolecules 1998, 31, $4309-4318$

(12) Choi, J.; Rubner, M. F. Influence of the Degree of Ionization on Weak Polyelectrolyte Multilayer Assembly. Macromolecules 2005, 38, 116-124.

(13) Lavalle, P.; Vivet, V.; Jessel, N.; Decher, G.; Voegel, J.-C.; Mesini, P. J.; Schaaf, P. Direct Evidence for Vertical Diffusion and
Exchange Processes of Polyanions and Polycations in Polyelectrolyte Multilayer Films. Macromolecules 2004, 37, 1159-1162.

(14) Salomäki, M.; Vinokurov, I. A.; Kankare, J. Effect of Temperature on the Buildup of Polyelectrolyte Multilayers. Langmuir 2005, 21, 11232-11240.

(15) Ruths, J.; Essler, F.; Decher, G.; Riegler, H. Polyelectrolytes I: Polyanion/Polycation Multilayers at the Air/Monolayer/Water Interface as Elements for Quantitative Polymer Adsorption Studies and Preparation of Hetero-Superlattices on Solid Surfaces. Langmuir 2000, 16, 8871-8878.

(16) McAloney, R. A.; Sinyor, M.; Dudnik, V.; Goh, M. C. Atomic Force Microscopy Studies of Salt Effects on Polyelectrolyte Multilayer Film Morphology. Langmuir 2001, 17, 6655-6663.

(17) Porcel, C.; Lavalle, P.; Ball, V.; Decher, G.; Senger, B.; Voegel, J.-C.; Schaaf, P. From Exponential to Linear Growth in Polyelectrolyte Multilayers. Langmuir 2006, 22, 4376-4383.

(18) Guo, Y.; Geng, W.; Sun, J. Layer-by-Layer Deposition of Polyelectrolyte-Polyelectrolyte Complexes for Multilayer Film Fabrication. Langmuir 2009, 25, 1004-1010.

(19) Podsiadlo, P.; Michel, M.; Lee, J.; Verploegen, E.; Wong Shi Kam, N.; Ball, V.; Lee, J.; Qi, Y.; Hart, A. J.; Hammond, P. T.; Kotov, N. A. Exponential Growth of LBL Films with Incorporated Inorganic Sheets. Nano Lett. 2008, 8, 1762-1770.

(20) Hong, J.; Park, H. Fabrication and Characterization of Block Copolymer Micelle Multilayer Films Prepared Using Dip-, Spin- and Spray-Assisted Layer-by-Layer Assembly Deposition. Colloids Surf., A 2011, 381, 7-12.

(21) Michel, M.; Izquierdo, A.; Decher, G.; Voegel, J.-C.; Schaaf, P.; Ball, V. Layer by Layer Self-Assembled Polyelectrolyte Multilayers with Embedded Phospholipid Vesicles Obtained by Spraying: Integrity of the Vesicles. Langmuir 2005, 21, 7854-7859.

(22) Boudou, T.; Crouzier, T.; Ren, K.; Blin, G.; Picart, C. Multiple Functionalities of Polyelectrolyte Multilayer Films: New Biomedical Applications. Adv. Mater. 2010, 22, 441-467.

(23) Paci, J. T.; Belytschko, T.; Schatz, G. C. Computational Studies of the Structure, Behavior upon Heating, and Mechanical Properties of Graphite Oxide. J. Phys. Chem. C 2007, 111, 18099-18111.

(24) Forati, T.; Atai, M.; Rashidi, A. M.; Imani, M.; Behnamghader, A. Physical and Mechanical Properties of Graphene Oxide/ polyethersulfone Nanocomposites. Polym. Adv. Technol. 2013, 25, $322-328$.

(25) Kotov, N. A.; Dékány, I.; Fendler, J. H. Ultrathin graphite oxide-polyelectrolyte composites prepared by self-assembly: Transition between conductive and non-conductive states. Adv. Mater. 1996, 8, 637-641.

(26) Kovtyukhova, N. I.; Ollivier, P. J.; Martin, B. R.; Mallouk, T. E.; Chizhik, S. A.; Buzaneva, E. V.; Gorchinskiy, A. D. Layer-by-Layer Assembly of Ultrathin Composite Films from Micron-Sized Graphite Oxide Sheets and Polycations. Chem. Mater. 1999, 11, 771-778.

(27) Zhao, X.; Zhang, Q.; Hao, Y.; Li, Y.; Fang, Y.; Chen, D. Alternate Multilayer Films of Poly(vinyl Alcohol) and Exfoliated Graphene Oxide Fabricated via a Facial Layer-by-Layer Assembly. Macromolecules 2010, 43, 9411-9416.

(28) Kuilla, T.; Bhadra, S.; Yao, D.; Kim, N. H.; Bose, S.; Lee, J. H. Recent Advances in Graphene Based Polymer Composites. Prog. Polym. Sci. 2010, 35, 1350-1375.

(29) Potts, J. R.; Dreyer, D. R.; Bielawski, C. W.; Ruoff, R. S. Graphene-Based Polymer Nanocomposites. Polymer 2011, 52, 5-25.

(30) Rodahl, M.; Kasemo, B. A Simple Setup to Simultaneously Measure the Resonant Frequency and the Absolute Dissipation Factor of a Quartz Crystal Microbalance. Rev. Sci. Instrum. 1996, 67, 32383241.

(31) Höök, F.; Kasemo, B.; Nylander, T.; Fant, C.; Sott, K.; Elwing, H. Variations in Coupled Water, Viscoelastic Properties, and Film Thickness of a Mefp-1 Protein Film during Adsorption and CrossLinking: A Quartz Crystal Microbalance with Dissipation Monitoring, Ellipsometry, and Surface Plasmon Resonance Study. Anal. Chem. 2001, 73, 5796-5804. 
(32) Shpigel, N.; Levi, M. D.; Sigalov, S.; Daikhin, L.; Aurbach, D. In Situ Real-Time Mechanical and Morphological Characterization of Electrodes for Electrochemical Energy Storage and Conversion by Electrochemical Quartz Crystal Microbalance with Dissipation Monitoring. Acc. Chem. Res. 2018, 51, 69-79.

(33) Salomäki, M.; Loikas, K.; Kankare, J. Effect of Polyelectrolyte Multilayers on the Response of a Quartz Crystal Microbalance. Anal. Chem. 2003, 75, 5895-5904.

(34) Salomäki, M.; Kankare, J. Specific Anion Effect in Swelling of Polyelectrolyte Multilayers. Macromolecules 2008, 41, 4423-4428.

(35) Salomäki, M.; Kankare, J. Influence of Synthetic Polyelectrolytes on the Growth and Properties of Hyaluronan-Chitosan Multilayers. Biomacromolecules 2009, 10, 294-301.

(36) Kankare, J. Sauerbrey Equation of Quartz Crystal Microbalance in Liquid Medium. Langmuir 2002, 18, 7092-7094.

(37) Sauerbrey, G. Verwendung von Schwingquarzen zur Wägung dünner Schichten und zur Mikrowägung. Z. Phys. Chem. 1959, 155, 206-222.

(38) Salomäki, M.; Räsänen, M.; Leiro, J.; Huti, T.; Tenho, M.; Lukkari, J.; Kankare, J. Oxidative Inorganic Multilayers for Polypyrrole Film Generation. Adv. Funct. Mater. 2010, 20, 21402147.

(39) Salomäki, M.; Myllymäki, O.; Hätönen, M.; Savolainen, J.; Lukkari, J. Layer-by-Layer Assembled Oxidative Films as General Platform for Electrodeless Formation of Conducting Polymers. ACS Appl. Mater. Interfaces 2014, 6, 2325-2334.

(40) Salomäki, M.; Tupala, M.; Parviainen, T.; Leiro, J.; Karonen, M.; Lukkari, J. Preparation of Thin Melanin-Type Films by SurfaceControlled Oxidation. Langmuir 2016, 32, 4103-4112.

(41) Xiong, H.; Cheng, M.; Zhou, Z.; Zhang, X.; Shen, J. A New Approach to the Fabrication of a Self-Organizing Film of Heterostructured Polymer/Cu2S Nanoparticles. Adv. Mater. 1998, $10,529-532$.

(42) Meier, A.; Hoffmann, K.; El-Hashani, A.; Tieke, B. Electrostatic and Coordinative Supramolecular Assembly of Functional Films for Electronic Application and Materials Separation. In Multilayer Thin Films. Sequential Assembly of Nanocomposite Materials; Decher, G.; Schlenoff, J. B., Eds.; Wiley- VCH: Weinheim, Germany, 2012; pp 473-509.

(43) Krieger, G.; Tieke, B. Coordinative Layer-by-Layer Assembly of Thin Films Based on Metal Ion Complexes of Ligand-Substituted Polystyrene Copolymers and Their Use as Separation Membranes. Macromol. Chem. Phys. 2017, 218, 1700052.

(44) Zhu, Y.; Xuan, H.; Ren, J.; Liu, X.; Zhao, B.; Zhang, J.; Ge, L. Humidity responsive self-healing based on intermolecular hydrogen bonding and metal-ligand coordination. RSC Adv. 2016, 6, 8975789763.

(45) Maier, A.; Tieke, B. Coordinative Layer-by-Layer Assembly of Electrochromic Thin Films Based on Metal Ion Complexes of Terpyridine-Substituted Polyaniline Derivatives. J. Phys. Chem. B 2012, 116, 925-934.

(46) Viinikanoja, A.; Lukkari, J.; Ääritalo, T.; Laiho, T.; Kankare, J. Phosphonic Acid Derivatized Polythiophene: A Building Block for Metal Phosphonate and Polyelectrolyte Multilayers. Langmuir 2003, 19, 2768-2775.

(47) Hirata, M.; Gotou, T.; Horiuchi, S.; Fujiwara, M.; Ohba, M. Thin-film particles of graphite oxide 1:High-yield synthesis and flexibility of the particles. Carbon 2004, 42, 2929-2937.

(48) Kankare, J.; Loikas, K.; Salomäki, M. Method for Measuring the Losses and Loading of a Quartz Crystal Microbalance. Anal. Chem. 2006, 78, 1875-1882.

(49) Salomäki, M.; Kankare, J. Modeling the Growth Processes of Polyelectrolyte Multilayers Using a Quartz Crystal Resonator. J. Phys. Chem. B 2007, 111, 8509-8519.

(50) Salomäki, M.; Kankare, J. Quartz Crystal Resonator as a Tool for Following the Build-up of Polyelectrolyte Multilayers. In Multilayer Thin Films - Sequential Assembly of Nanocomposite Materials; Decher, G.; Schlenoff, J. B., Eds.; Wiley-VCH, 2012; pp 455-469.
(51) Kulkarni, D. D.; Choi, I.; Singamaneni, S. S.; Tsukruk, V. V. Graphene Oxide-Polyelectrolyte Nanomembranes. ACS Nano 2010, 4, 4667-4676.

(52) Yang, M.; Hou, Y.; Kotov, N. A. Graphene-Based Multilayers: Critical Evaluation of Materials Assembly Techniques. Nano Today 2012, 7, 430-447.

(53) Qi, W.; Xue, Z.; Yuan, W.; Wang, H. Layer-by-Layer Assembled Graphene Oxide Composite Films for Enhanced Mechanical Properties and Fibroblast Cell Affinity. J. Mater. Chem. B 2014, 2, 325-331.

(54) Sham, A. Y. W.; Notley, S. M. Layer-by-Layer Assembly of Thin Films Containing Exfoliated Pristine Graphene Nanosheets and Polyethyleneimine. Langmuir 2014, 30, 2410-2418.

(55) Sham, A. Y. W.; Notley, S. M. Graphene-polyelectrolyte multilayer film formation driven by hydrogen bonding. J. Colloid Interface Sci. 2015, 456, 32-41.

(56) Ermakov, A.; Lim, S. H.; Gorelik, S.; Kauling, A. P.; de Oliveira, R. V. B.; Castro Neto, A. H.; Glukhovskoy, E.; Gorin, D. A.; Sukhorukov, G. B.; Kiryukhin, M. V. Polyelectrolyte-Graphene Oxide Multilayer Composites for Array of Microchambers Which Are Mechanically Robust and Responsive to NIR Light. Macromol. Rapid Commun. [Online early access]. DOI: 10.1002/marc.201700868. Published online: March 25, 2018.

(57) Lukkari, J.; Salomäki, M.; Ääritalo, T.; Loikas, K.; Laiho, T.; Kankare, J. Preparation of Multilayers Containing Conjugated Thiophene-Based Polyelectrolytes. Layer-by-Layer Assembly and Viscoelastic Properties. Langmuir 2002, 18, 8496-8502.

(58) Schöche, S.; Hong, N.; Khorasaninejad, M.; Ambrosio, A.; Orabona, E.; Maddalena, P.; Capasso, F. Optical Properties of Graphene Oxide and Reduced Graphene Oxide Determined by Spectroscopic Ellipsometry. Appl. Surf. Sci. 2017, 421, 778-782.

(59) Kauppila, J.; Lund, L.; Laiho, T.; Salomäki, M.; Kankare, J.; Lukkari, J. Effective Low Temperature Reduction of Graphene Oxide with vanadium(III). J. Mater. Chem. C 2014, 2, 3602.

(60) Wang, S.; Sun, H.; Ang, H. M.; Tadé, M. O. Adsorptive Remediation of Environmental Pollutants Using Novel GrapheneBased Nanomaterials. Chem. Eng. J. 2013, 226, 336-347.

(61) Nazaraly, M.; Wallez, G.; Chanéac, C.; Tronc, E.; Ribot, F.; Quarton, M.; Jolivet, J.-P. The First Structure of a Cerium(IV) Phosphate: Ab Initio Rietveld Analysis of CeIV(PO4)(HPO4)0.5(H2O)0.5. Angew. Chem., Int. Ed. 2005, 44, 5691-5694.

(62) Compton, O. C.; Nguyen, S. T. Graphene Oxide, Highly Reduced Graphene Oxide, and Graphene: Versatile Building Blocks for Carbon-Based Materials. Small 2010, 6, 711-723.

(63) Xiong, R.; Hu, K.; Grant, A. M.; Ma, R.; Xu, W.; Lu, C.; Zhang, X.; Tsukruk, V. V. Ultrarobust Transparent Cellulose NanocrystalGraphene Membranes with High Electrical Conductivity. Adv. Mater. 2016, 28, 1501-1509.

(64) Müller, W. E. G.; Ackermann, M.; Tolba, E.; Neufurth, M.; Wang, S.; Schröder, H. C.; Wang, X. A Bio-Imitating Approach to Fabricate an Artificial Matrix for Cartilage Tissue Engineering Using Magnesium-Polyphosphate and Hyaluronic Acid. RSC Adv. 2016, 6, 88559-88570.

(65) McCullough, J. F.; Van Wazer, J. R.; Griffith, E. J. Structure and Properties of the Condensed Phosphates. XI. Hydrolytic Degradation of Graham's Salt. J. Am. Chem. Soc. 1956, 78, 4528-4533.

(66) Menyo, M. S.; Hawker, C. J.; Waite, J. H. Rate-Dependent Stiffness and Recovery in Interpenetrating Network Hydrogels through Sacrificial Metal Coordination Bonds. ACS Macro Lett. 2015, 4, 1200-1204.

(67) Harrington, M. J.; Masic, A.; Holten-Andersen, N.; Waite, J. H.; Fratzl, P. Iron-Clad Fibers: A Metal-Based Biological Strategy for Hard Flexible Coatings. Science 2010, 328, 216-220.

(68) Holten-Andersen, N.; Harrington, M. J.; Birkedal, H.; Lee, B. P.; Messersmith, P. B.; Lee, K. Y. C.; Waite, J. H. pH-Induced MetalLigand Cross-Links Inspired by Mussel Yield Self-Healing Polymer Networks with near-Covalent Elastic Moduli. Proc. Natl. Acad. Sci. U. S. A. 2011, 108, 2651-2655. 
(69) Gu, D.; Fein, J. B. Adsorption of Metals onto Graphene Oxide: Surface Complexation Modeling and Linear Free Energy Relationships. Colloids Surf., A 2015, 481, 319-327.

(70) Ashour, R. M.; Abdelhamid, H. N.; Abdel-Magied, A. F.; AbdelKhalek, A. A.; Ali, M. M.; Uheida, A.; Muhammed, M.; Zou, X.; Dutta, J. Rare Earth Ions Adsorption onto Graphene Oxide Nanosheets. Solvent Extr. Ion Exch. 2017, 35, 91-103.

(71) Park, S.; Lee, K.-S.; Bozoklu, G.; Cai, W.; Nguyen, S. T.; Ruoff, R. S. Graphene Oxide Papers Modified by Divalent Ions-Enhancing Mechanical Properties via Chemical Cross-Linking. ACS Nano 2008, 2, 572-578.

(72) Pourbeyram, S. Effective Removal of Heavy Metals from Aqueous Solutions by Graphene Oxide-Zirconium Phosphate (GOZr-P) Nanocomposite. Ind. Eng. Chem. Res. 2016, 55, 5608-5617.

(73) Baranik, A.; Sitko, R.; Gagor, A.; Queralt, I.; Marguí, E.; Zawisza, B. Graphene Oxide Decorated with Cerium(IV) Oxide in Determination of Ultratrace Metal Ions and Speciation of Selenium. Anal. Chem. 2018, 90, 4150-4159.

(74) Szulgit, G. K.; Shadwick, R. E. Dynamic Mechanical Characterization of a Mutable Collagenous Tissue: Response of Sea Cucumber Dermis to Cell Lysis and Dermal Extracts. J. Exp. Biol. 2000, 203, 1539-1550.

(75) Capadona, J. R.; Shanmuganathan, K.; Tyler, D. J.; Rowan, S. J.; Weder, C. Stimuli-Responsive Polymer Nanocomposites Inspired by the Sea Cucumber Dermis. Science 2008, 319, 1370-1374.

(76) Jackson, A. C.; Beyer, F. L.; Price, S. C.; Rinderspacher, B. C.; Lambeth, R. H. Role of Metal-Ligand Bond Strength and Phase Separation on the Mechanical Properties of Metallopolymer Films. Macromolecules 2013, 46, 5416-5422.

(77) Schlenoff, J. B.; Ly, H.; Li, M. Charge and Mass Balance in Polyelectrolyte Multilayers. J. Am. Chem. Soc. 1998, 120, 7626-7634.

(78) Jomaa, H. W.; Schlenoff, J. B. Salt-Induced Polyelectrolyte Interdiffusion in Multilayered Films: A Neutron Reflectivity Study. Macromolecules 2005, 38, 8473-8480.

(79) Xiong, R.; Hu, K.; Zhang, S.; Lu, C.; Tsukruk, V. V. Ultrastrong Freestanding Graphene Oxide Nanomembranes with SurfaceEnhanced Raman Scattering Functionality by Solvent-Assisted Single-Component Layer-by-Layer Assembly. ACS Nano 2016, 10, 6702-6715.

(80) Degen, I. A. Tables of Characteristic Group Frequences for the Interpretation of the Infrared and Raman Spectra; Acolyte Publications, 1997.

(81) Szczygieł, I.; Macalik, L.; Radomińska, E.; Znamierowska, T.; Mączka, M.; Godlewska, P.; Hanuza, J. Luminescence, Electronic Absorption and Vibrational IR and Raman Studies of Binary and Ternary Cerium Ortho-, Pyro- and Meta-Phosphates Doped with Pr3+ Ions. Opt. Mater. 2007, 29, 1192-1205.

(82) Ţucureanu, V.; Matei, A.; Avram, A. M. FTIR Spectroscopy for Carbon Family Study. Crit. Rev. Anal. Chem. 2016, 46, 502-520.

(83) Mahmud, H. N. M. E.; Kassim, A.; Zainal, Z.; Yunus, W. M. M. Fourier transform infrared study of polypyrrole-poly(vinyl alcohol) conducting polymer composite films: Evidence of film formation and characterization. J. Appl. Polym. Sci. 2006, 100, 4107-4113.

(84) Omastová, M.; Trchová, M.; Kovářová, J.; Stejskal, J. Synthesis and Structural Study of Polypyrroles Prepared in the Presence of Surfactants. Synth. Met. 2003, 138, 447-455.

(85) Ahonen, H. J.; Lukkari, J.; Kankare, J. n- and p-Doped Poly(3,4ethylenedioxythiophene): Two Electronically Conducting States of the Polymer. Macromolecules 2000, 33, 6787-6793.

(86) Chen, X.; Inganäs, O. Three-Step Redox in Polythiophenes: Evidence from Electrochemistry at an Ultramicroelectrode. J. Phys. Chem. 1996, 100, 15202-15206.

(87) Bredas, J. L.; Street, G. B. Polarons, Bipolarons, and Solitons in Conducting Polymers. Acc. Chem. Res. 1985, 18, 309-315. 